\title{
Introduction to the Special Issue on School Psychology and the Common Core State Standards
}

\author{
Barbara J. D'Incau ${ }^{1}$
}

Published online: 15 April 2015

(C) California Association of School Psychologists 2015

One of the most salient features of our contemporary society is the speed at which technologies and world events evolve. Changes in our social institutions, especially education, present both inspiring opportunities and formidable challenges for educators, parents, and students. The Common Core State Standards (CCSS) Initiative is the most ambitious attempt to date to establish and institutionalize a national set of high expectations for what students in kindergarten through 12 th grade should be able to achieve at each grade level to be ready for college and the twenty-first century workforce (http:// www.npr.org/blogs/ed/2014/05/27/307755798/the-commoncore-faq.)

The Standards, which currently cover mathematics and English language arts, were developed by the National Governors Association and the Council of Chief State School Officers, with input from teachers, school administrators, and education experts from 48 states (Sloan 2010). The Standards are internationally benchmarked and supported by evidence showing that students' mastery of them leads to preparation for the workforce and higher education. By 2012, 46 states and the District of Columbia had adopted these new standards (Education Week 2012).

Locally and nationally, the implementation of CCSS is an opportunity to significantly improve educational practices and positively impact student achievement. The promise of CCSS is that education would inspire students who are already proficient to reach even higher levels, while providing supports for students who are not proficient, including those with special needs, to improve their skills and close the achievement gap. In the transition to Common Core, and as states, districts

Barbara J. D'Incau

barbaradincau@mac.com

1 School Psychologist, Ventura, CA, USA and schools work to improve their students' ability to use math, language arts, and social-emotional skills for career and college readiness, many questions have arisen regarding training, implementation, pedagogy, curriculum, assessment, and evaluation.

In September 2014, California Association of School Psychologists (CASP) put out a call for scholarly articles for this special issue of Contemporary School Psychology titled School Psychology and the Common Core State Standards. CASP asked several questions about the impact of CCSS on the role and activities of school psychologists. These included the following:

- How will-how should - the new common core assessments and practices affect the training of school psychologists?

- What technology-based skills will students and teachers need? How will these affect assessment for students with special needs?

- How will the new teaching and learning processes affect multi-tiered systems of support, including RtI?

- How will referrals for special education and related services change? What do school psychologists need to know to participate in student study teams?

- How will the Smarter Balanced Assessment Consortium (SBAC) and other student evaluations affect assessments for special education and related services?

- What accommodations and modifications will be made for students with significant disabilities?

- How will school psychologists assist with intervention planning, progress monitoring and data collection?

At the time this Special Issue was published, the impact of CCSS and the outcomes for student learning are still largely unknown. The Standards were adopted in 2011 in most states, with implementation beginning between 2011 and 2014. State 
assessments under the Common Core framework were instituted for the first time in spring of 2014. For this reason, student data are not yet available for the new assessments. Also, curriculum development, course alignment, and teacher training are ongoing.

Given that so much continues to be unknown about CCSS, the four articles in this special issue provide an important starting point for School Psychologists to begin reflecting on how Common Core will impact the ways in which they think about their roles and the services they provide to schools. These articles address various aspects of School Psychology and the Common Core, including the impact of teaching the standards with students with autism and potential challenges to social-emotional learning with diverse students.

The first article (Marsh, 2015), examines the implementation of Common Core State Standards and teaching practices with a specific population of students, those identified with autism spectrum disorder. After reviewing core characteristics of autism as defined by DSM-5 (APA 2013) and Title V California Code of Regulations (Title V 2014), Marsh illustrates several methods by which teachers can present the concepts and skills defined by the grade-level standards, but modify the materials and assessment strategies to meet the specific needs of this group of students with moderate disabilities. Marsh suggests that special education teams should determine the students' characteristics that interfere with their ability to benefit from Common Core instruction, and develop strategies and supports to allow these students to access the Standards.

The second article (Gallagher and Odozi 2015) suggests a protocol for the assessment of Common Core teaching (Protocol for the Assessment of Common Core TeachingPROACCT), and examines the impact of instructional inclusion on students with special needs. The authors describe the critical role of the teacher and his/her pedagogy on instructional quality that results in student learning. Examples of students with special needs in general education classrooms are examined, with a focus on three dimensions: student participation, the cognitive demand of the lesson and tasks, and the academic language students use when they are discussing content.

The third article (Saeki et al. 2015), reviews research on highstakes testing under NCLB (U.S. Congress, 2002) and its effects on teacher wellness and occupational stability as well as instructional practices. The authors suggest that educational practices under CCSS may produce similar concerns. The school psychologist's role could include leadership, consultation, and support to assist schools and teachers.

The fourth article (Gubi and Bocanegra 2015) proposes that social-emotional learning (SEL) will be compromised under CCSS, especially for diverse students. The article outlines the benefits of SEL, which is not only valuable in and of itself, but which also has been found to enhance academic learning. The authors caution that the Common Core initiative may inadvertently hinder student achievement.
It is my hope that this special issue of Contemporary School Psychology will inspire and extend conversations and collaboration of school psychologists and other educators in the implementation of the Common Core State Standards for all our students. As school psychologists, we possess unique skills and training in consultation, assessment, and program evaluation; as such, we are capable of making significant contributions to this effort. The importance of our role cannot be overstated.

Finally, I would like to express my gratitude to journal Editor-in-Chief Michael Hass, Ph.D., and the staff of Springer Publications, especially Mr. Jesson Austria, for their guidance and assistance throughout the process of putting together this special issue. I also wish to extend my deep appreciation to the authors for their timely and professional response to the call for submissions. Additionally, this issue would not be possible without the dedication and thorough reading and constructive comments by the educational professionals who served as peer reviewers for the manuscripts. Together, you have advanced the profession of School Psychology.

\section{References}

American Psychiatric Association. (2013). Diagnostic and Statistical Manual of Mental Disorders, Fifth Ed. Washington, DC: Author.

California Code of Regulations, Title V. (2014). Available: http://www. casponline.org.

Education Week. (2012). Common Standards Adoption and Assessment, from Education Week Spotlight on Implementing Common Core Standards (2013). www.edweek.org.

Gallagher, K. L., \& Odozi, A. (2015). Protocol for the assessment of common core teaching: the impact of instructional inclusion on students with special needs. Contemporary School Psychology. doi:10. 1007/s40688-015-0052-z.

Gubi, A. A., \& Bocanegra, J. O. (2015). Impact of the common core on social-emotional learning initiatives with diverse students. Contemporary School Psychology. doi:10.1007/s40688015-0045-y

Marsh, W. W. (2015). Common core and the uncommon learner: how autism affects acquisition of common core state standards. Contemporary School Psychology. doi:10.1007/ s40688-015-0048-8

NPR Ed. (2014). The Common Core FAQ. Available: http://www.npr. org/blogs/ed/2014/05/27/307755798/the-common-core-faq.

Saeki, E., Pendergast L., Segool N. K., von der Embse, N. P. (2015). Potential psychosocial and instructional consequences of the common core state standards: implications for research and practice. Contemporary School Psychology. doi:10.1007/ s40688-014-0043-5

Sloan, W. (2010). Coming to Terms with Common Core Standards. ASCD InfoBrief, 15 (4).

U.S. Congress. (2002). Public Law 107-110. No Child Left Behind Act of 2001. Washington, DC: Author.

Barbara J. D'Incau Ph.D., NCSP, is a Licensed Educational Psychologist, School Psychologist, and Grant Writer working in the Tri-Counties Region of Southern California. She is the founder and director of 
ChildSource, a consortium of health, education, and social services providers working to promote, develop, and evaluate systems of care for children, youth, families, schools, and communities. Dr. D'Incau specializes in both grant development and also individual educational assessments for students with special needs. She has obtained over \$43 million in funded grant projects for schools, districts, individuals, and nonprofit organizations. Dr. D'Incau has held Adjunct Professor positions in the Counseling/Clinical/School Psychology Department at University of
California, Santa Barbara and in Education and Psychology at California Lutheran University. She maintains a bilingual (English/Spanish) private practice in Educational Psychology, specializing in the evaluation and treatment of individuals, preschool through adult with attention-deficit/ hyperactivity disorder (ADHD), learning disabilities, perinatal drug/ alcohol exposure, traumatic brain injury, and emotional and behavioral disorders. Dr. D'Incau is the current President of the California Association of School Psychologists (2014-2015). 